\title{
Continuous glucose monitoring in the management of patients after gastric bypass
}

\author{
Marcela Rodríguez Flores ${ }^{1}$, Ruth Carmina Cruz Soto², Verónica Vázquez Velázquez¹, Reina Ruth Soriano Cortés , \\ Carlos Aguilar Salinas ${ }^{3,4}$ and Eduardo García García1
}

1Obesity and Eating Disorders Clinic, Instituto Nacional de Ciencias Médicas y Nutrición Salvador Zubirán, 2Nutrition and Obesity Center, Centro Médico ABC, ${ }^{3}$ Metabolic Diseases Research Unit, Instituto Nacional de Ciencias Médicas y Nutrición Salvador Zubirán, Mexico City, Mexico, and ^Endocrinology and Metabolism Department, Instituto Tecnológico de Estudios Superiores de Monterrey Tec Salud, Instituto Nacional de Ciencias Médicas y Nutrición Salvador Zubirán, Mexico City, Mexico

Correspondence should be addressed to M Rodríguez Flores Email

chelorf76@yahoo.com

\section{Summary}

In patients with gastric bypass (GB), high glucose variability (GV) and hypoglycemia have been demonstrated, which could impact the metabolic status and eating behavior. We describe the glucose patterns determined through continuous glucose monitoring (CGM) in two patients with $>5$ years follow-up after GB and significant weight recovery, who reported hypoglycemic symptoms that interfered with daily activities, and their response to a nutritional and psycho-educative prescription. Case 1: A 40-year-old woman without pre-surgical type 2 diabetes (T2DM) and normal HbA1C, in whom CGM showed high GV and hypoglycemic episodes that did not correlate with the time of hypoglycemic symptoms. Her GV reduced after prescription of a diet with low glycemic index and modification of meal patterns. Case 2: A 48-yearold male with pre-surgical diagnosis of T2DM and current normal HbA1c, reported skipping meals. The CGM showed high GV, 15\% of time in hypoglycemia and hyperglycemic spikes. After prescription of a low glycemic index diet, his GV increased and time in hypoglycemia decreased. Through the detailed self-monitoring needed for CGM, we discovered severe anxiety symptoms, consumption of simple carbohydrates and lack of meal structure. He was referred for more intensive psychological counseling. In conclusion, CGM can detect disorders in glucose homeostasis derived both from the mechanisms of bariatric surgery, as well as the patient's behaviors and mental health, improving decision-making during follow-up.

\section{Learning points:}

- High glycemic variability is frequent in patients operated with gastric bypass.

- Diverse eating patterns, such as prolonged fasting and simple carbohydrate ingestion, and mental health disorders, including anxiety, can promote and be confused with worsened hypoglycemia.

- CGM requires a detailed record of food ingested that can be accompanied by associated factors (circumstances, eating patterns, emotional symptoms). This allows the detection of particular behaviors and amount of dietary simple carbohydrates to guide recommendations provided within clinical care of these patients.

\section{Background}

Bariatric surgery is the most effective treatment to achieve significant and sustained weight loss in patients with moderate and severe obesity and to attain better control of comorbidities compared with diet and exercise.
The gastrointestinal tract is a critical organ for glucose homeostasis, and mixed bariatric procedures such as GB modify different metabolic pathways, as well as hunger and satiety signals (1). Changes in secretion of intestinal 
peptides, including glucagon-like peptide type 1 (GLP-1) and gastric inhibitory peptide (GIP), are considered among the main mechanisms that promote improvement in glucose and insulin levels (2). Nevertheless, new regulation of glucose metabolism in subjects with GB can also provoke adverse symptoms derived from the altered gastrointestinal function, predisposing to abrupt variability in glucose levels, reportedly higher than those in subjects with type 2 diabetes (T2DM) (3). The term dumping is used to refer to disturbances associated with the adrenergic discharge that occurs with the dilatation of the intestinal loops and to abrupt change in glucose concentrations. Reactive hypoglycemia has been reported in almost two-thirds of these patients, regardless of the diabetes status before surgery (4). These are some of the most common side effects following GB, associated with reduced quality of life and disordered eating behaviors, including responsive carbohydrate consumption and exacerbated insulin secretion.

Continuous glucose monitoring (CGM) performed in patients operated with GB has found significant GV, defined as the maximum/minimum index of glucose levels in $24 \mathrm{~h}$, accompanied by significant hyperglycemic spikes, whetherin the presenceor absenceof hypoglycemia (5), and elevation of glucose concentrations above $300 \mathrm{mg} / \mathrm{dL}$ after one of these events. Hanaire et al. found values of the mean amplitude of glycemic excursions (MAGEs) among patients operated with GB of $86 \pm 58(\mathrm{mg} / \mathrm{dL})$ and in patients with diabetes of $66 \pm 24$, respectively (3), compared with values reported for Hispanic population of $21.6 \pm 12.6$ obtained from a multiethnic study (6). Continuous glucose monitoring has also been helpful to confirm the presence of hypoglycemia in patients with and without symptoms of neuroglycopenia after bariatric surgery (5). Two studies have assessed the response of short-term interventions (acarbose and/or reduction in carbohydrate consumption) to reduce hypoglycemic symptoms and GV in patients with GB with favorable results $(7,8)$. Nevertheless, studies of $\mathrm{GV}$ in this population which is rapidly increasing are still limited. This technology is broadly employed in the management of diabetes mellitus, mainly type 1 , for its capacity to achieve goals of glycemic control in comparison with multiple measurements of capillary glucose. The capacity to measure detailed glucose patterns has led to the recognition of both GV and hypoglycemia as adverse factors for metabolic and weight control and to impulse their identification and management. These phenomena are not likely to be detected by conventional follow-up, and are imperative to treat, given their potential to influence weight, eating patterns, quality of life and cardiovascular outcomes.

We describe patterns of GV (maximum interstitial glucose (IG), time to postprandial peak IG (TP) and MAGE, assessed using Easy GV( software) by CGM in two patients, one female and a male, who we selected for reporting significant hypoglycemic symptoms associated with significant weight recovery (WR) after GB, and the effect of a nutritional and psycho-educative intervention.

\section{Case presentation}

\section{Case 1}

A 40-year-old woman without T2DM before surgery, and pre-surgical BMI of $41.65 \mathrm{~kg} / \mathrm{m}^{2}$. Her pre-surgical weight was $101.4 \mathrm{~kg}$, and she achieved a postoperative weight of $68.8 \mathrm{~kg}$. Two years later, she started a pregnancy weighing $80 \mathrm{~kg}$, developing frequent hypoglycemic symptoms that persisted after the pregnancy. At the baseline visit in this study, she had 6 years of follow-up after bariatric surgery, and her weight was $102.7 \mathrm{~kg}$, a $49 \%$ increase from her minimum weight after surgery.

\section{Case 2}

A 48-year-old male with diagnosis of T2DM treated with metformin before surgery, microalbuminuria and BMI of $40.3 \mathrm{~kg} / \mathrm{m}^{2}$. His pre-surgical weight was $137.8 \mathrm{~kg}$ and he achieved $89.6 \mathrm{~kg} 7$ months after surgery. One year after surgery, he developed hypoglycemic symptoms related with prolonged fasting due to stress at work. In the initial visit at this study, he had 5 years of follow-up after bariatric surgery, and his weight was $107.8 \mathrm{~kg}$ (BMI of $32 \mathrm{~kg} / \mathrm{m}^{2}$ ), a $20 \%$ increase from his minimum weight after surgery.

\section{Investigation}

\section{Case 1}

At the first CGM, BMI was $35.1 \mathrm{~kg} / \mathrm{m}^{2}$ and $\mathrm{HbA1c}$ was $5.4 \%$. Metabolic parameters were triglycerides $67 \mathrm{mg} / \mathrm{dL}$, total cholesterol $182 \mathrm{mg} / \mathrm{dL}$, HDL cholesterol $66 \mathrm{mg} / \mathrm{dL}$, LDL cholesterol $103 \mathrm{mg} / \mathrm{dL}$, folic acid $26.4 \mathrm{ng} / \mathrm{mL}$, Vit B12 $464 \mathrm{pg} / \mathrm{mL}$, ferritin $10.1 \mathrm{ng} / \mathrm{mL}$, vitamin D $45.1 \mathrm{ng} / \mathrm{mL}$. She complained of hypoglycemic symptoms and therefore a 2-h glucose tolerance test was performed, in which values for glucose/insulin were the following: basal 58/4.6, $30 \mathrm{~min} 183 / 80.6,60 \mathrm{~min}$ 173/100.2, 
$90 \min 101 / 48.7,2$ h 51/12.2, 3 h 44/2.4, 4 h 70/2.2 and 5 h $81 / 2.8(\mathrm{mg} / \mathrm{dL} / \mu \mathrm{UI} / \mathrm{mL})$.

\section{Case 2}

His $\mathrm{HbA1c}$ was 5.6\% and he reported the need to consume carbohydrate-rich foods due to frequent symptoms of diaphoresis and light-headedness. Fasting glucose/insulin were $94 / 8.47 \mathrm{mg} / \mathrm{dL} / \mu \mathrm{UI} / \mathrm{mL}$, 2-h postprandial glucose was $79 \mathrm{mg} / \mathrm{dL}$, triglycerides $75 \mathrm{mg} / \mathrm{dL}$, total cholesterol $125 \mathrm{mg} / \mathrm{dL}$, HDL cholesterol $49 \mathrm{mg} / \mathrm{dL}$, LDL cholesterol $59 \mathrm{mg} / \mathrm{dL}$, folic acid $24.2 \mathrm{ng} / \mathrm{mL}$, vitamin B12 $308 \mathrm{pg} / \mathrm{mL}$, ferritin $7.4 \mathrm{ng} / \mathrm{mL}$, vitamin D $15.1 \mathrm{ng} / \mathrm{mL}$ and albumin/creatinine ratio was $1.9 \mathrm{mg} / \mathrm{g}$.

\section{Treatment}

\section{Case 1}

In a 4-day CGM, mean IG was $91.2 \pm 27.8 \mathrm{mg} / \mathrm{dL}$, maximum IG was $217 \mathrm{mg} / \mathrm{dL}$, minimum IG $48 \mathrm{mg} / \mathrm{dL}$, with $15 \%$ of time with $<70 \mathrm{mg} / \mathrm{dL}$, TP was $39 \mathrm{~min}$ and MAGE was $65.4 \mathrm{mg} / \mathrm{dL}$ (Fig. 1). Through selfmonitoring, she reported frequent prolonged fasting and consumption of simple carbohydrates. She reported hypoglycemic symptoms manifested by dizziness that did not correlate with sensor-detected hypoglycemia, and she was asymptomatic at night, when she did present hypoglycemia. The nutritionist prescribed a diet with low-glycemic index underscoring certain carbohydrate sources (such as sushi) that provoked the highest glucose peaks and reduction of fasting time. The second CGM showed mean glucose of $93.7 \pm 22.7 \mathrm{mg} / \mathrm{dL}$, maximum IG of $184 \mathrm{mg} / \mathrm{dL}$ and minimum IG of $62 \mathrm{mg} / \mathrm{dL}$; TP was $35 \mathrm{~min}$ and MAGE was $48.08 \mathrm{mg} / \mathrm{dL}$ (Fig. 2).

\section{Case 2}

In a 5-day CGM, mean glucose was $96.8 \pm 29.5 \mathrm{mg} / \mathrm{dL}$, maximum IG was $195 \mathrm{mg} / \mathrm{dL}$, minimum glucose value $50 \mathrm{mg} / \mathrm{dL}$, with $5 \%$ of time with $<60 \mathrm{mg} / \mathrm{dL}$, TP was $40 \mathrm{~min}$ and MAGE was $68.6 \mathrm{mg} / \mathrm{dL}$ (Fig. 3). In his self-monitoring, he reported a diet with adequate quality but frequent prolonged fasting. After prescription of a diet with low glycemic index and reduction of fasting, the second CGM reported mean glucose of $115.1 \pm 67.9 \mathrm{mg} / \mathrm{dL}$, maximum IG of $400 \mathrm{mg} / \mathrm{dL}$, minimum IG of $46 \mathrm{mg} / \mathrm{dL}$, with $3 \%$ of time with glucose $<60 \mathrm{mg} / \mathrm{dL}$, TP was $35 \mathrm{~min}$ and MAGE was $127.2 \mathrm{mg} / \mathrm{dL}$ (Fig. 4). He reported constant anxiety and binge of carbohydrate-rich beverages. Accordingly, management was directed toward more intensive psychological counseling to increase stressreducing activities, and identification/modification of dysfunctional responses, including substitution of usually consumed carbohydrates with foods with lower glycemic index.

\section{Outcome and follow-up}

\section{Case 1}

The patient lost $5.5 \mathrm{~kg}$ during the following 6 months and reports she has struggled to maintain adequate meal

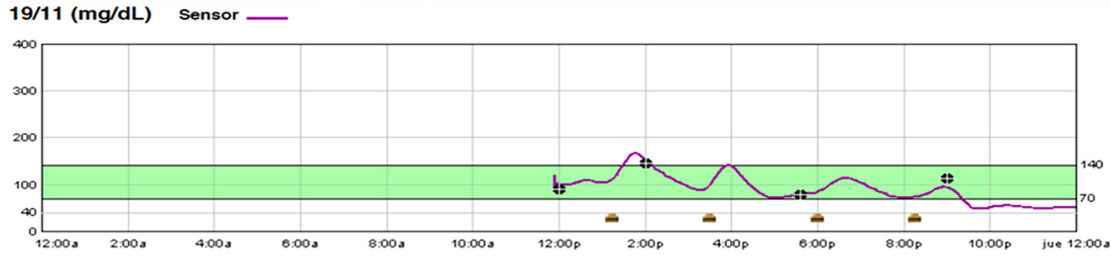

20/11 (mg/dL) Sensor —

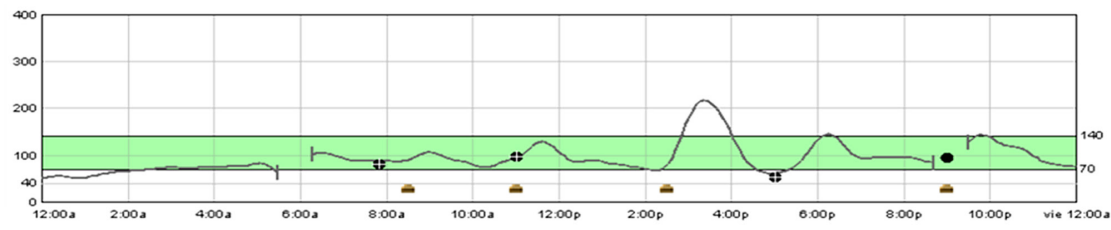

21/11 (mg/dL) Sensor

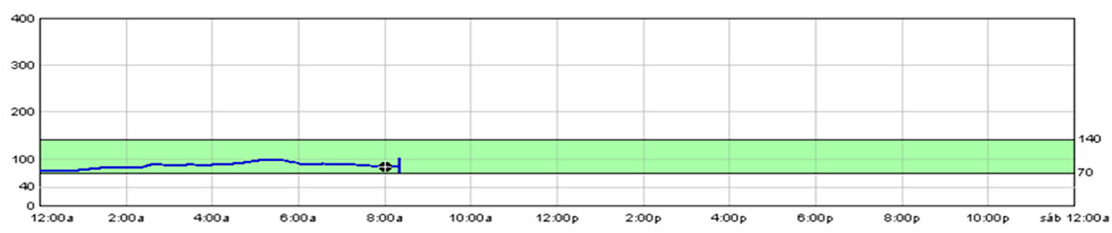

Figure 1

Basal CGM, case 1. 
21/11 (mg/dL) Sensor

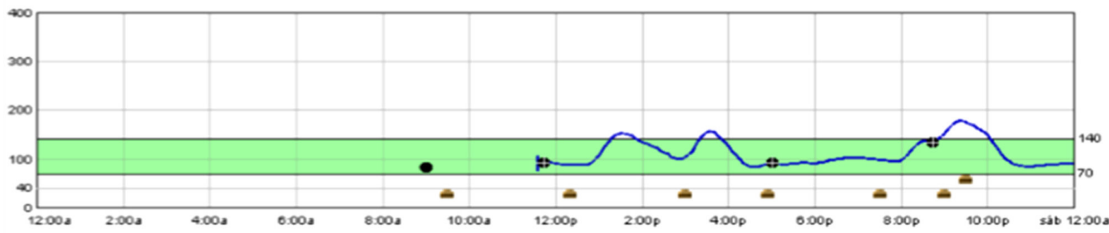

22/11 (mg/dL) Sensor

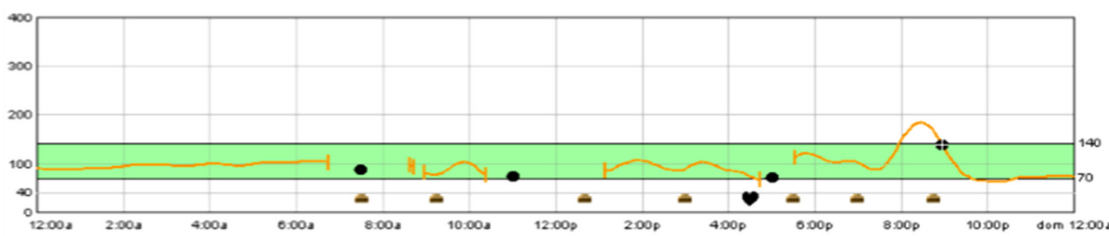

23/11 (mg/dL) Sensor

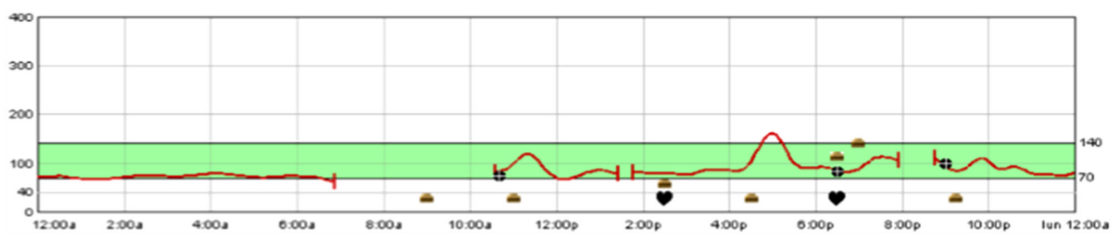

Figure 2

Second CGM, case 1.

structure but maintains some safety measures such as food provisions on most active days.

\section{Case 2}

The patient started attending monthly group sessions for patients with bariatric surgery, in which he has managed to overcome severe dysfunctional behaviors and thoughts toward meal patterns, achieving greater coping skills and reporting infrequent periods of hypoglycemia.

\section{Discussion}

CGM provides dynamic information of disorders in glucose homeostasis linked with complex metabolic responses, the eating behavior and mental health in the context of bariatric surgery (Table 1). With its use, we detected hyperglycemia not correlated with symptoms, significant GV and complex behaviors when trying to confirm the presence of hypoglycemia and its associated factors during management of our patients. These factors are often hard to detect by conventional

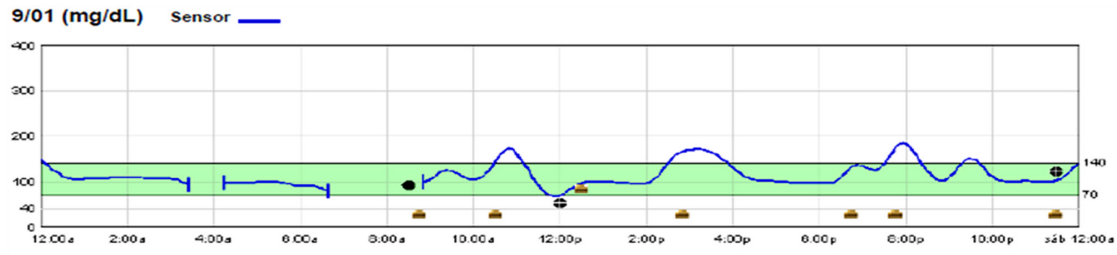

$10 / 01$ (mg/dL) Sensor
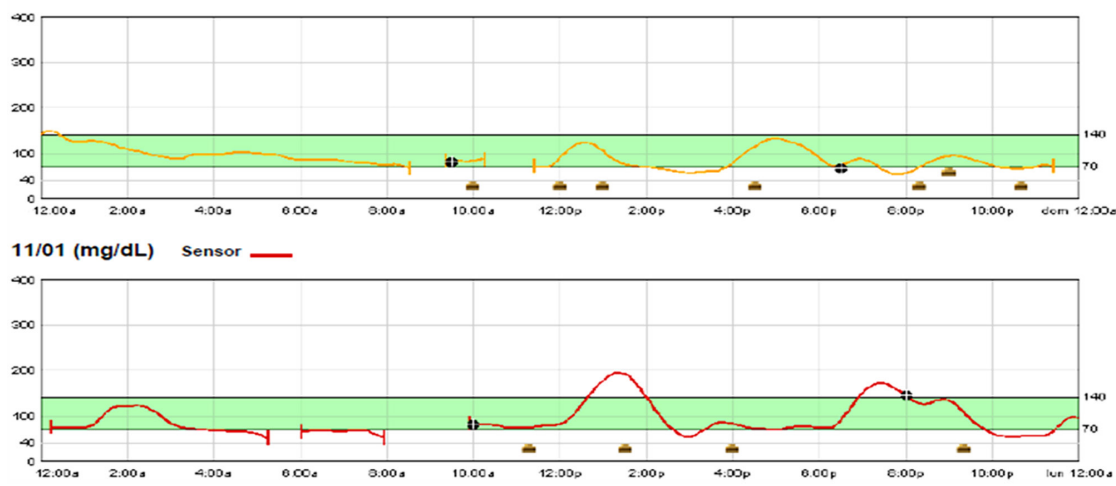

Figure 3

Basal CGM, case 2. 
$16 / 01(\mathrm{mg} / \mathrm{dL})$ Sensor

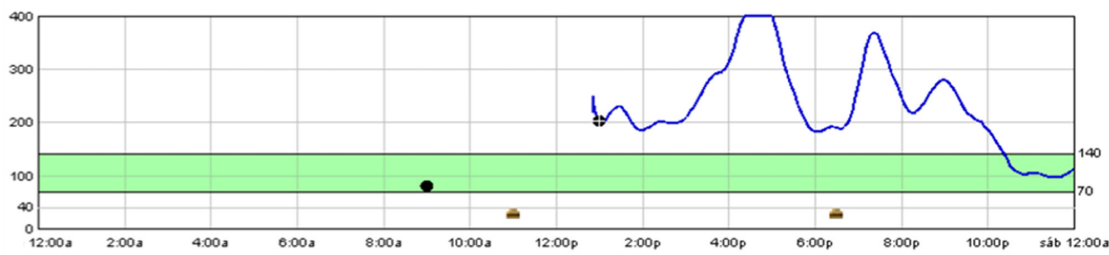

$17 / 01(\mathrm{mg} / \mathrm{dL}) \quad$ Sensor

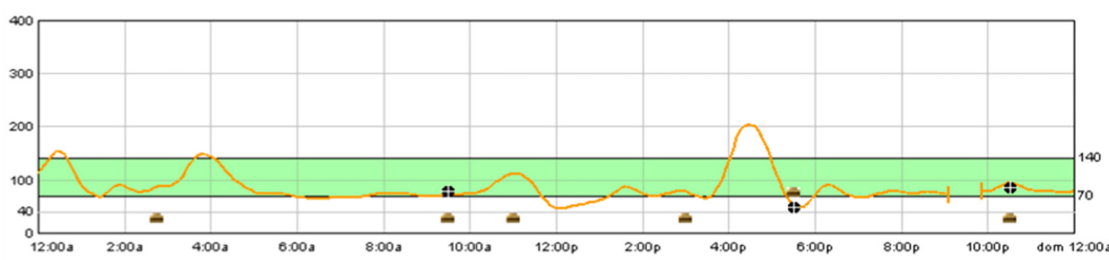

$18 / 01(\mathrm{mg} / \mathrm{dL})$ Sensor

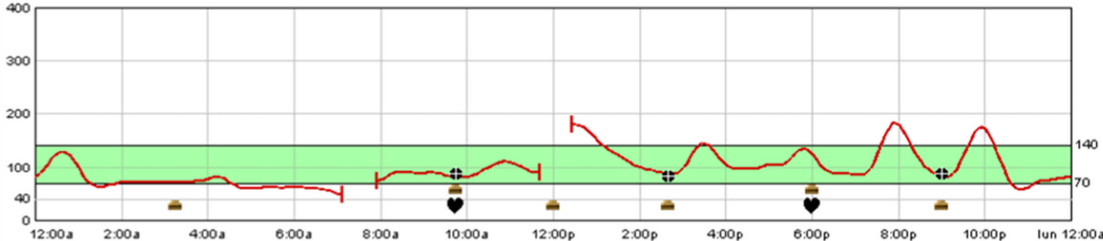

\section{Figure 4}

Second CGM, case 2 . follow-up, undetected by HbA1c and often do not correlate with hypo- and hyperglycemic spikes (8), which could potentially influence weight regain, disordered eating patterns and potentially adverse cardiovascular outcomes.

Several studies have reported novel findings through CGM in patients with bariatric surgery that underscore the great prevalence of hypoglycemia $(6,9)$ and aids in the reduction, but not normalization of $\mathrm{GV}$ and hypoglycemia after acarbose administration and low glycemic index diets $(9,10)$. In this study, the use of this technology aided in the recognition of different mechanisms associated with disordered eating behaviors that commonly promote glucose shifts and carbohydrate consumption in subjects with bariatric surgery. Additionally, in our experience, this tool increased the treatment satisfaction and motivation of the patients, making them more informed and prepared for solving problems during follow-up.
We consider the use of CGM as a valuable method to identify potentially harmful glucose disorders in this population, including causes of decompensation. This seems particularly useful in subjects who manifest persistent hypoglycemic symptoms and limited diet structure despite adequate nutritional prescriptions. Information obtained through its selfmonitoring provides a practical psycho-educational tool that brings together medical and self-care strategies to be implemented on eating behaviors to improve individual decision-making when addressing difficulties in follow-up, whether for weight goals, symptoms management and metabolic control. Strategies to improve the detection and management of complications arising after GB is relevant, given the increasing number of people who will undergo this treatment the following years, who will need adequate follow-up to avoid unfavorable outcomes,

Table 1 Continuous glucose monitoring data in two subjects with gastric bypass.

\begin{tabular}{|c|c|c|c|}
\hline & & nterstitial & \\
\hline & Mean & Minimum & Maximum \\
\hline Case 1 & & & \\
\hline 1st CGM & 91 & 48 & 217 \\
\hline 2nd CGM & 94 & 62 & 184 \\
\hline Case 2 & & & \\
\hline 1st CGM & 96 & 50 & 195 \\
\hline 2nd CGM & 115 & 46 & 400 \\
\hline
\end{tabular}

\begin{tabular}{c}
\hline \multicolumn{2}{c}{ Time sp } \\
\hline$>140 \mathrm{mg} / \mathrm{dL}$ \\
$6 \%$ \\
$6 \%$ \\
$9 \%$ \\
$21 \%$ \\
\hline
\end{tabular}

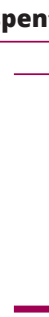

$<70 \mathrm{mg} / \mathrm{dL}$
$15 \%$
$5 \%$
$15 \%$
$13 \%$

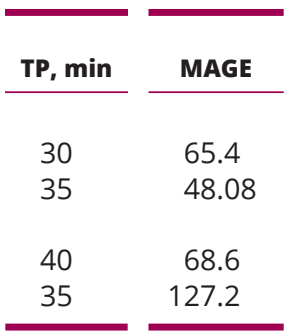

IG, interstitial glucose; TP, time to postprandial peak. 
involving control of comorbidities, secondary effects, weight loss and regain and quality of life.

\section{Declaration of interest}

M Rodríguez Flores, V Vázquez Velázquez and E García García have received honoraria from Novo Nordisk. The other authors have nothing to disclose.

\section{Funding}

This work was supported by the Medtronic Scientific Research Grand NERP14-006, which provided the iPro CGM system as an investigator initiated study. Financing of additional material was provided by the Obesity and Eating Disorders Clinic, Instituto Nacional de Ciencias Médicas y Nutrición Salvador Zubirán.

\section{Patient consent}

Written informed consent was obtained from both patients for publication of the submitted article.

\section{Author contribution statement}

M Rodríguez Flores, R C Cruz Soto, V Vázquez Velázquez, R Soriano Cortés and E García García developed the protocol. M Rodríguez Flores, R C Cruz Soto, V Vázquez Velázquez and R Soriano Cortés performed the clinical interventions. M Rodríguez Flores and C Aguilar Salinas analyzed the data and wrote the manuscript. All authors have reviewed and approved the content of the manuscript.

\section{References}

1 Sheng B, Truong K, Spitler H, Zhang L, Tong X \& Chen L. The long-term effects of bariatric surgery on Type 2 diabetes remission, microvascular and macrovascular complications, and mortality: a systematic review and meta-analysis. Obesity Surgery 201727 2724-2732. (https://doi.org/10.1007/s11695-017-2866-4)

2 Vidal J, Corcelles R, Jimenez A, Flores L \& Lacy AM. Metabolic and bariatric surgery for obesity. Gastroenterology 2017152 1780-1790. (https://doi.org/10.1053/j.gastro.2017.01.051)

3 Hanaire H, Bertrand M, Guerci B, Anduze Y, Guillaume E \& Ritz P. High glycemic variability assessed by continuous glucose monitoring after surgical treatment of obesity by gastric bypass. Diabetes Technology and Therapeutics 201113 625-630. (https://doi. org/10.1089/dia.2010.0203)

4 Salehi M, Gastaldelli A \& D'Alessio DA. Altered islet function and insulin clearance cause hyperinsulinemia in gastric bypass patients with symptoms of postprandial hypoglycemia. Journal of Clinical Endocrinology and Metabolism 201499 2008-2017. (https://doi. org/10.1210/jc.2013-2686)

5 Halperin F, Patti ME, Skow M, Bajwa M \& Goldfine AB. Continuous glucose monitoring for evaluation of glycemic excursions after gastric bypass. Journal of Obesity 20112011 869536. (https://doi. org/10.1155/2011/869536)

6 Nielsen JB, Abild CB, Pedersen AM, Pedersen SB \& Richelsen B. Continuous glucose monitoring after gastric bypass to evaluate the glucose variability after a low-carbohydrate diet and to determine hypoglycemia. Obesity Surgery 201626 2111-2118. (https://doi. org/10.1007/s11695-016-2058-7)

7 Beck RW, Riddlesworth T, Ruedy K, Ahmann A, Bergenstal R, Haller S, Kollman C, Kruger D, McGill JB, Polonsky W, et al. Effect of continuous glucose monitoring on glycemic control in adults with type 1 diabetes using insulin injections: the DIAMOND randomized clinical trial. JAMA 2017317 371-378. (https://doi.org/10.1001/ jama.2016.19975)

8 Ohrstrom CC, Worm D \& Hansen DL. Postprandial hyperinsulinemic hypoglycemia after Roux-en-Y gastric bypass: an update. Surgery for Obesity and Related Diseases 201713 345-351. (https://doi. org/10.1016/j.soard.2016.09.025)

9 Abrahamsson N, Eden Engstrom B, Sundbom M \& Karlsson FA. Hypoglycemia in everyday life after gastric bypass and duodenal switch. European Journal of Endocrinology 2015173 91-100. (https:// doi.org/10.1530/EJE-14-0821)

10 Hanaire H, Dubet A, Chauveau ME, Anduze Y, Fernandes M, Melki V \& Ritz P. Usefulness of continuous glucose monitoring for the diagnosis of hypoglycemia after a gastric bypass in a patient previously treated for type 2 diabetes. Obesity Surgery 201020 126-129. (https://doi.org/10.1007/s11695-009-9975-7)

Received in final form 30 April 2019

Accepted 26 June 2019 